\title{
ANÁLISE TÉCNICA DE BLOCOS CERÄMICOS DE VEDACÃO COMERCIALIZADOS EM BRASÍLIA-DF CONFORME A NBR 15270/2017
}

\author{
SILVA. MAYKON V. \\ Engenheiro Civil \\ Universidade Católica de Brasília \\ Distrito Federal, Brasil \\ eng.maykonsilva@gmail.com \\ CUNHA. LIDIA R. R. \\ Graduanda de Engenharia Civil \\ Universidade Católica de Brasília \\ Distrito Federal, Brasil \\ lidiaraquelrocha@hotmail.com
}

\author{
NOBRE. GUILHERME G. \\ Engenheiro Civil \\ Universidade Católica de Brasília \\ Dsitrito Federal, Brasil \\ gui.gnobre@gmail.com
}

\author{
SOUZA, NELSON L. DE Q. \\ Engenheiro Civil \\ Universidade Católica de Brasília \\ Distrito Federal, Brasil \\ nelsonbrazdequeiroz@hotmail.com
}

\section{RESUMO}

Os blocos cerâmicos, conhecidos popularmente como tijolos, são um dos componentes básicos de qualquer construção de alvenaria, seja ela de vedação ou estrutural. Contudo, em muitos casos, a fabricação desse material é realizada sem controle de qualidade. Dessa forma, esse trabalho busca avaliar a qualidade de blocos comercializados em Brasília, utilizando como referência a NBR15270/2017. Foram realizados ensaios para análise das propriedades físicas e mecânicas. Os resultados obtidos demonstram que a maioria das amostras estão em conformidade com o ensaio de absorção, porém no caso da resistência à compressão, os valores apresentados ficaram abaixo do mínimo exigido em duas das amostras analisadas. Foi verificado que todos os blocos seriam reprovados, por apresentarem divergência de pelo menos um requisito normativo. Isso confirma a necessidade de investimentos por parte das indústrias de cerâmicas em tecnologia para automação da produção e controle da qualidade dos seus produtos, pois a produção atual é praticamente artesanal.

Palavras-chave: bloco cerâmico, qualidade, bloco de vedação.

\section{ABSTRACT}

Ceramic blocks, popularly known as bricks, are one of the basic components of any masonry construction, be it sealing or structural. However, in many cases, the manufacture of this material is carried out without quality control. Thus, this work seeks to evaluate the quality of blocks sold in Brasília, using NBR15270 / 2017 as a reference. Tests were carried out to analyze the physical and mechanical properties. The results obtained demonstrate that most of the samples are in accordance with the absorption test, however in the case of compressive strength, the values presented were below the minimum required in two of the analyzed samples. It was found that all blocks would be disapproved, as they differ from at least one normative requirement. This confirms the need for investments by the ceramic industries in technology for production automation and quality control of their products, as the current production is practically handmade.

Keywords: ceramic block, quality, block seal..

\section{INTRODUÇÃO}

A indústria da construção civil, uma das mais importantes do Brasil é caracterizada pelos altos índices de desperdícios, custos elevados de produção e mão de obra desqualificada. Desta maneira existe a necessidade de acompanhar o processo de desenvolvimento das outras indústrias, e inovar nos métodos e materiais utilizados. Como no caso da indústria de blocos cerâmicos que nessecita se modernisar, onde os métodos ultilizados em alguns locais do país são arcaicos.

Apesar do estudo se tratar dos blocos cerâmicos de Brasília, um estudo realizado por Morais e Sposto (2006), relatam que a qualidade dos blocos cerâmicos produzidos em Goiás frequentemente deixa a desejar. Muitos fatores são responsáveis por isto, dentre eles o elevado teor de umidade dos blocos que são levados a queima, ocasionando defeitos tais como trincas por retração. Os autores também mencionam que as indústrias dessa região empregam temperaturas de queima inadequadas (inferiores a $950^{\circ} \mathrm{C}$ ), o que compromete a fase de sinterização do corpo cerâmico, consequentemente diminuindo a resistência dos blocos. 
Estudos realizados enfocando a gerência de canteiros de obras da indústria da construção civil mostram que perto da metade de todos os distúrbios encontrados envolviam deficiências na qualidade dos materiais (ANDRADE, 2002). Mostrando a necessidade de um controle melhor da qualidade de seus produtos, pois esse fator esta intimamente ligado as patologias encontradas em obras.

As manifestações patológicas são também responsáveis por uma parcela importante da manutenção, de modo que grande parte das intervenções de manutenção nas edificações poderia ser evitada se houvesse um melhor detalhamento do projeto e da escolha apropriada dos materiais e componentes da construção (COSTA, 2001).

Visando a segurança e a aplicação das normas técnicas pela indústria, propoem-se analisar as propriedades de um dos materiais mais utilizados na construção civil, o bloco cerâmico de vedação produzido na região do Distrito Federal.

\section{METODOLOGIA DE AVALIAÇÃO}

Todo o estudo será baseado na ABNT NBR 15270:2017 que define os termos e fixa os requisitos dimensionais, físicos e mecânicos exigíveis no recebimento de blocos cerâmicos de vedação a serem utilizados em obras de alvenaria de vedação, com ou sem revestimento.

Como a própria norma define, bloco cerâmico de vedação é o componente da alvenaria de vedação que possui furos prismáticos perpendiculares às faces que os contêm. É produzido para ser usado especificamente com furos na horizontal, mas também pode ser produzido para utilização com furos na vertical. Os blocos cerâmicos para vedação constituem as alvenarias externas ou internas que não têm a função de resistir a outras cargas verticais, além do peso da alvenaria da qual faz parte.

\subsection{Requisitos Gerais}

\subsubsection{Fabricação}

O bloco cerâmico de vedação deve ser fabricado por conformação plástica de matéria-prima argilosa, contendo ou não aditivos, e queimado a elevadas temperaturas.

\subsubsection{Identificação}

O bloco cerâmico de vedação deve trazer, obrigatoriamente, gravado em uma das suas faces externas, a identificação do fabricante e do bloco, em baixo relevo ou reentrância, com caracteres de no mínimo 5 mm de altura, sem que prejudique o seu uso.

Nessa inscrição deve constar no mínimo o seguinte:

a) identificação da empresa;

b) dimensões de fabricação em centímetros, na sequência largura (L), altura (H) e comprimento (C), na forma (L x H x C), podendo ser suprimida a inscrição da unidade de medida em centímetros.

Segundo a norma, o bloco cerâmico de vedação não deve apresentar defeitos sistemáticos, tais como quebras, superfícies irregulares ou deformações que impeçam o seu emprego na função especificada. As características visuais do bloco cerâmico face-à-vista devem atender aos critérios de avaliação da aparência especificados.

\subsection{Características Geométricas}

\subsubsection{Medidas das faces (dimensões efetivas)}

A norma explica como deve ser feito os ensaios e os pontos para obtenção dos valores da largura (L), altura (H) e comprimento $(\mathrm{C})$. As medições devem ser feitas em dois pontos, medidas em milímetros e trabalharemos com a média destes dois valores. 


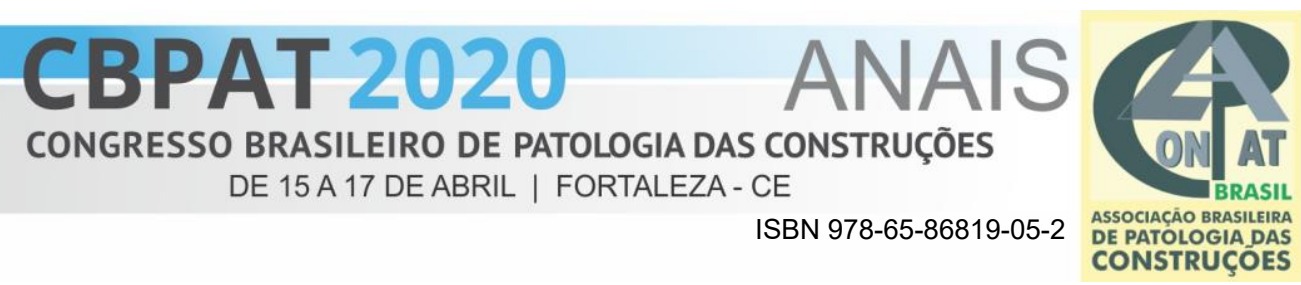

2.2.2 Espessura dos septos e paredes externas dos blocos

Os corpos-de-prova devem ser colocados sobre uma superfície plana e indeformável. A espessura das paredes externas deve ser medida no mínimo nos pontos indicados na figura 1, buscando o ponto onde a parede apresenta a menor espessura. As medições das espessuras dos septos devem ser obtidas na região central destes, utilizando no mínimo quatro medições, buscando os septos de menor espessura.

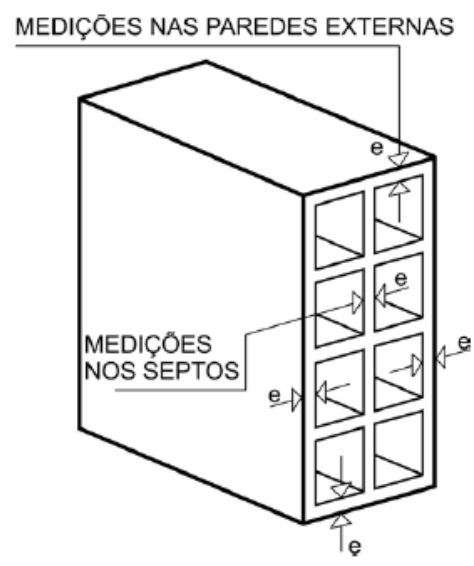

Figura 1: Medições nos septos e paredes externas dos blocos. Fonte: NBR 15270:2017

A figura 2 apresenta medições das paredes externas dos blocos e seus septos realizadas em laboratório.

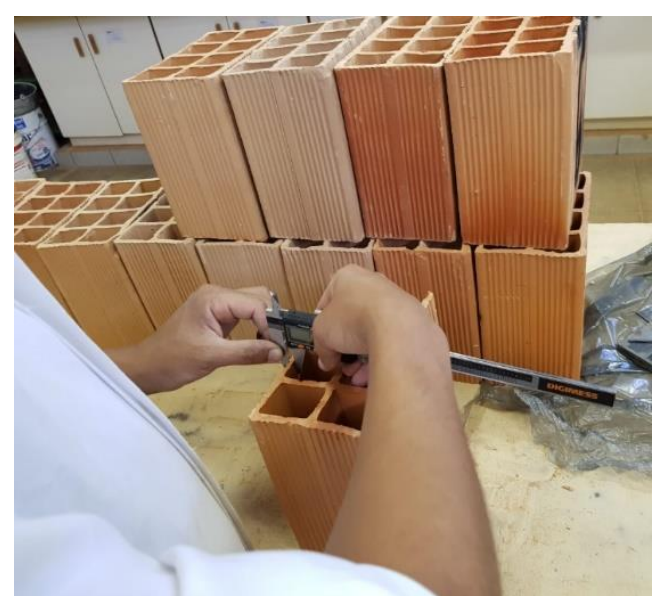

Figura 2: Medições realizadas em laboratório dos septos e das paredes externas dos blocos.

2.2.3 Desvio em relação ao esquadro (D)

Deve-se medir o desvio em relação ao esquadro entre uma das faces destinadas ao assentamento e a maior face destinada ao revestimento do bloco, conforme a figura 3 , empregando-se o esquadro metálico e a régua metálica. 


\section{СВРAT 2020

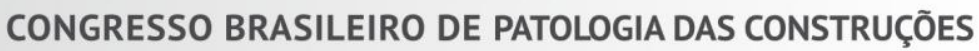 \\ DE 15 A 17 DE ABRIL | FORTALEZA - CE}
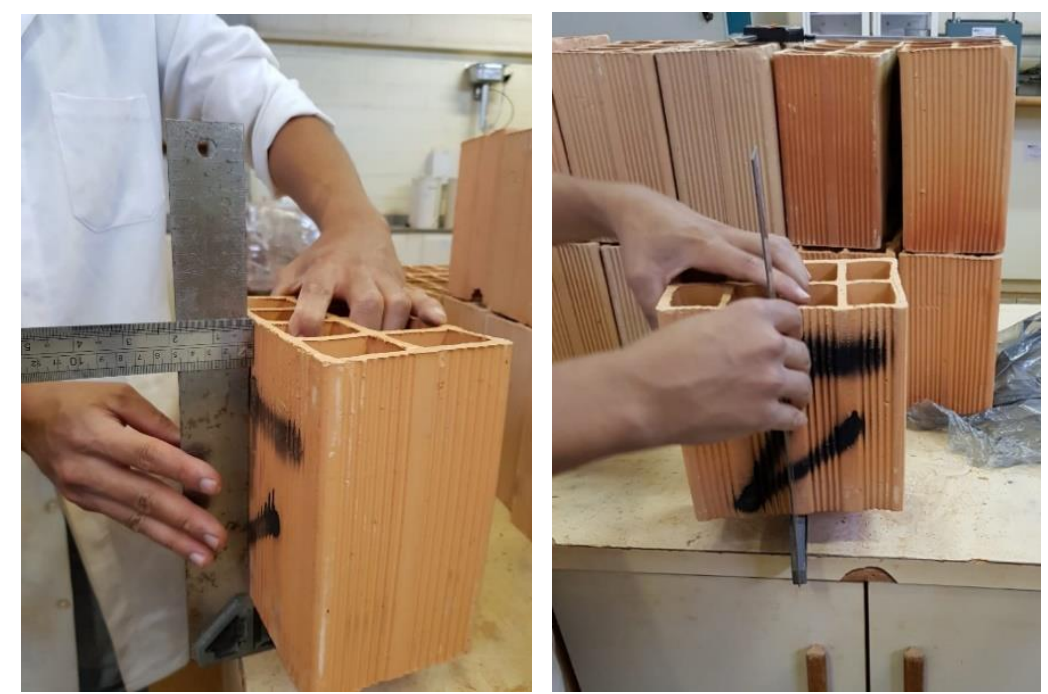

Figura 3: Desvio em relação ao esquadro, medido em laboratório.

2.2.4 Planeza das faces $(\mathrm{F})$

Deve-se determinar a planeza de uma das faces destinadas ao revestimento através da flecha formada na diagonal, conforme as figuras 4 , empregando-se o esquadro metálico e a régua metálica.
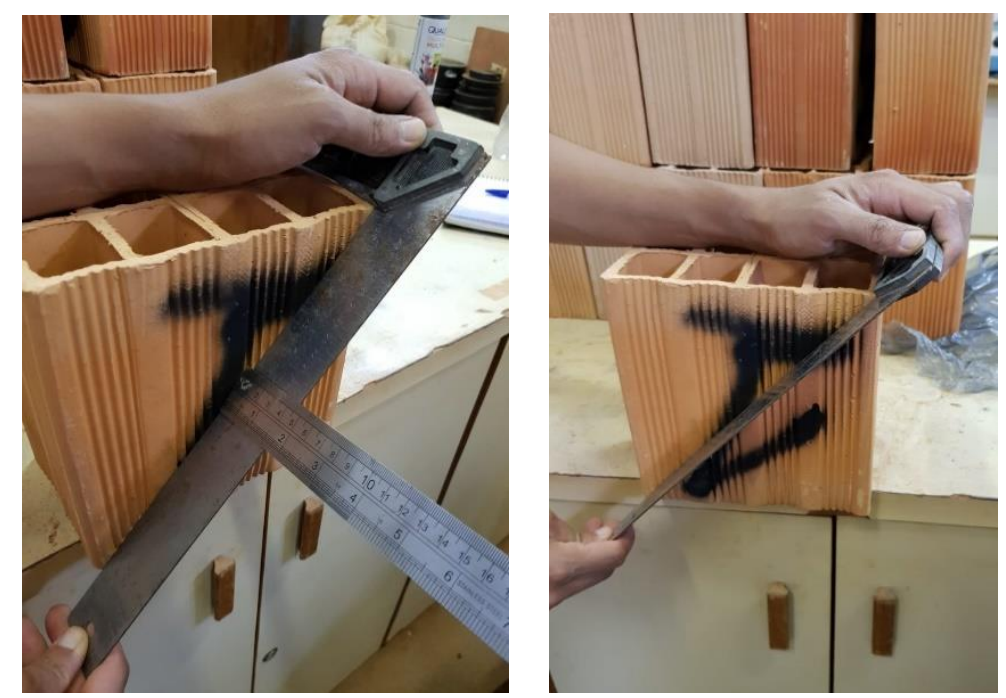

Figura 4: Planeza das faces, medição no laboratório

\subsection{5 Área bruta}

A determinação da área bruta é aplicável para o bloco de vedação e estrutural e a determinação da área líquida exclusivamente para bloco estrutural. A área bruta de cada bloco é obtida pela expressão L (Largura) x C (Comprimento), expressa em centímetros quadrados, com aproximação decimal.

\subsection{Características físicas}

\subsection{1 Índice de absorção de água}

O índice de absorção d'água (A) de cada corpo-de-prova é determinado pela expressão:

$$
\mathrm{AA}(\%)=\frac{\mathrm{m}_{\mathrm{u}}-\mathrm{m}_{\mathrm{s}}}{\mathrm{m}_{\mathrm{s}}} \cdot 100
$$


Onde:

mu - Massa úmida do corpo-de-prova $(\mathrm{g})$

ms - Massa do corpo-de-prova seco em estufa ( $g$ );

\subsection{Caracteristica Mecânica}

A característica mecânica dos blocos cerâmicos de vedação é a resistência à compressão individual (Fb). Todos os corposde-prova devem ser ensaiados de modo que a carga seja aplicada na direção do esforço que o bloco deve suportar durante o seu emprego, sempre perpendicular ao comprimento e na face destinada ao assentamento. Foi realizado capeamento dos corpos-de-prova e o rompimento dos mesmos feitos segundo os procedimentos da NBR 15270:2017. Na figura 5, observa-se um bloco cerâmico capeado e em seguida posicionado na prensa hidráulica para a realização do ensaio de resistência à compressão.
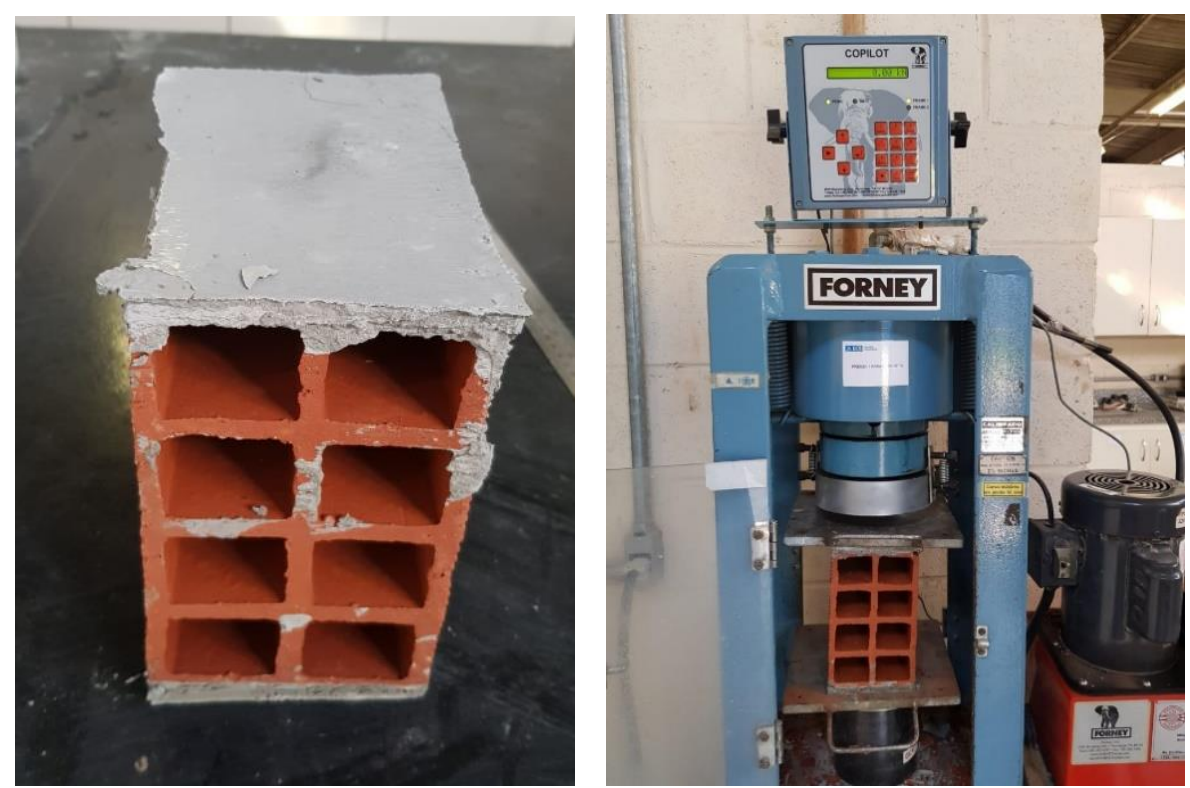

Figura 5: Corpo de prova capeado e saturado, posicionado na prensa hidráulica

\subsection{Requisitos específicos}

Para avaliar todos estes parâmetros ou requisitos tratados acima, a norma NBR 15270-1:2005 divide esses requisitos em 6 pontos a fim de definir as variações toleráveis das amostras. Tolerâncias dimensionais (L, H, C), espessura dos septos e paredes externas, desvio em relação ao esquadro (D), planeza das faces ou flecha (F), resistência à compressão $(\mathrm{Fb})$, índice de absorção d'água (AA)

\subsection{Inspeção}

\subsubsection{Inspeção geral}

Para execução da inspeção geral adota-se amostragem simples para verificação dos blocos cerâmicos quanto a identificação da empresa e as dimensões de fabricação. Em seguida adota-se dupla amostragem para verificação visual da qualidade dos blocos, levando em consideração, superfícies irregulares, quebras, deformações e defeitos sistemáticos, sendo os lotes de fornecimento de 1000 até 100000 blocos.

\subsubsection{Inspeção por ensaios}

Na execução da inspeção por ensaios, adota-se amostragem simples. Para o ensaio de determinação das características geométricas (largura, altura, comprimento, espessura das paredes externas e septos, planeza das faces e desvio em relação ao esquadro) e para o ensaio de determinação da resistência à compressão, as amostras são constituídas de 13 corpos-deprova. Para o ensaio de determinação do índice de absorção d'água, a amostra é constituída de doze corpos-de-prova. 


\section{RESULTADOS E DISCUSSÃO}

Ao realizar análise das características visuais, foi possível verificar a presença clara de irregularidades, deformações Na Figura 7 apresenta-se os resultados obtidos para quebras, irregularidades e/ou deformações em cada um dos blocos cerâmicos pertencentes as amostras das marcas selecionadas, bem como, a indicação da empresa fabricante e dimensões de largura (L), altura (H) e comprimento (C) expressas nas faces dos blocos cerâmicos.

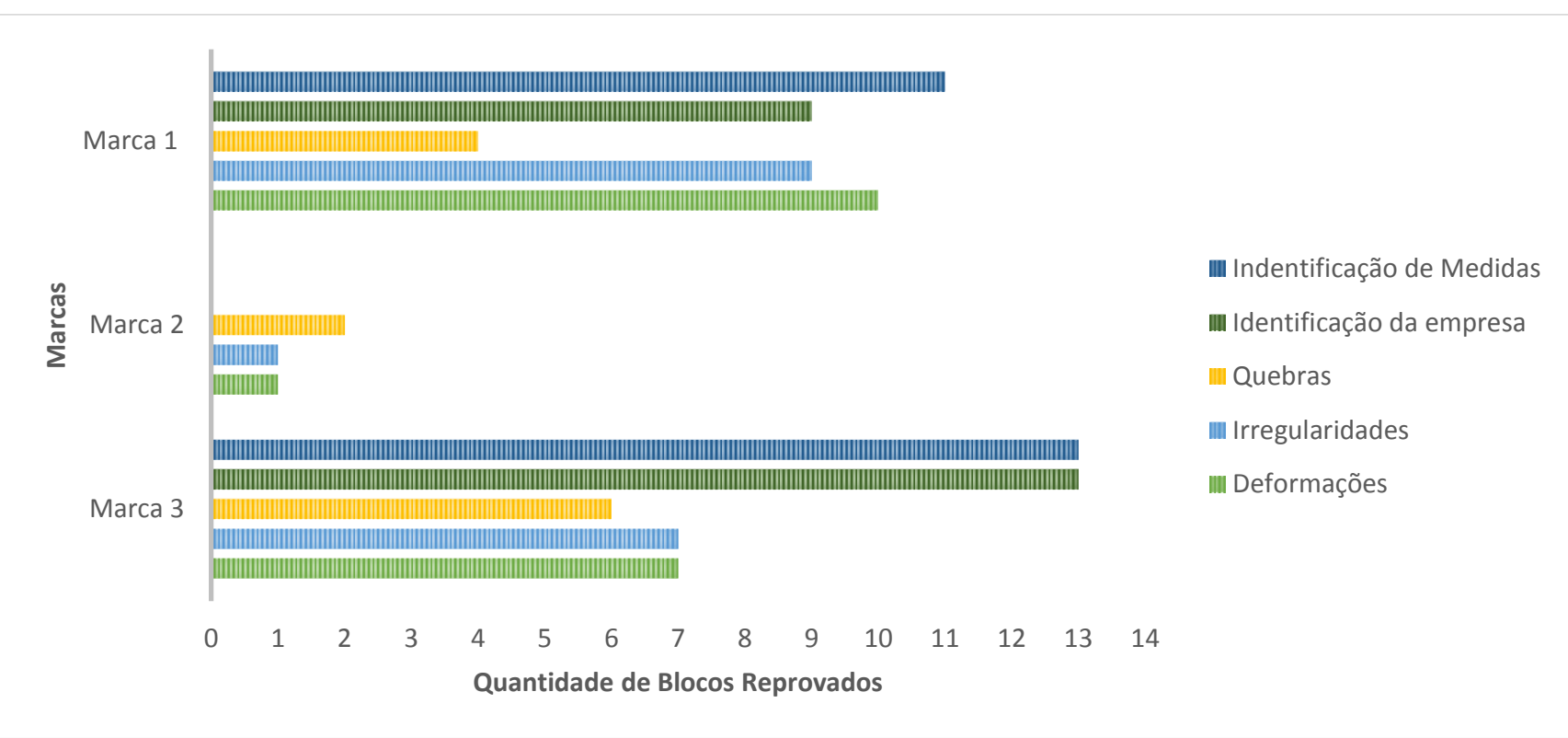

Figura 7 - Quantidade de blocos reprovados para cada um dos parâmetros de caracterização visual (identificação de medidas, identificação da empres, quebras, irregularidades e deformações).

Os resultados das características geométricas como aferições de dimensões efetivas em largura, altura e comprimento dos blocos reprovados nas amostras, espessura das paredes externas e septos, desvio em relação ao esquadro e planeza das faces estão representados, respectivamente nas Figuras 7,8 e 9.

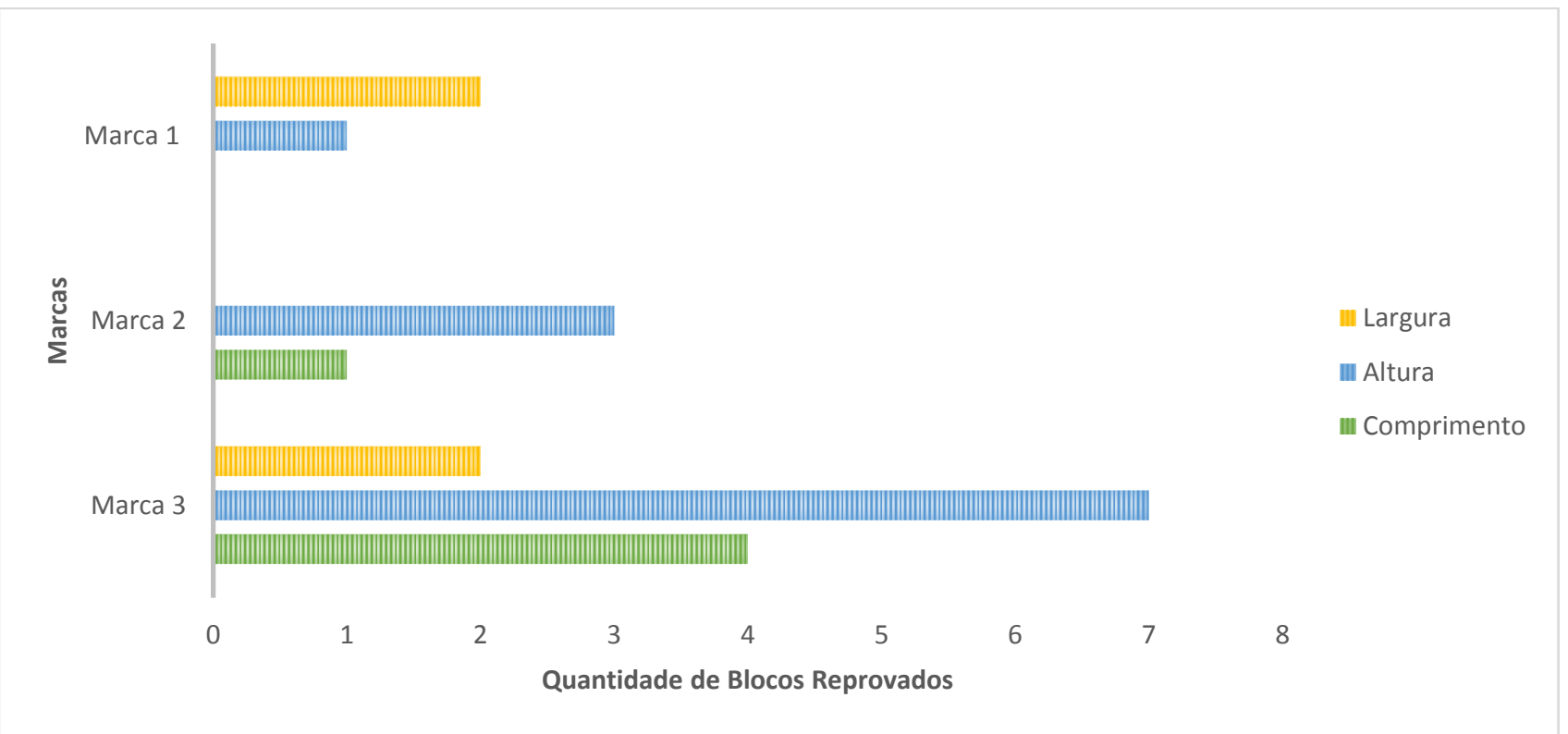

Figura 8 - Total de blocos cerâmicos com medidas excedentes a tolerância de $+/$ - $5 \mathrm{~mm}$ para o ensaio de dimensões efetivas (largura, altura e comprimento) conforme . 


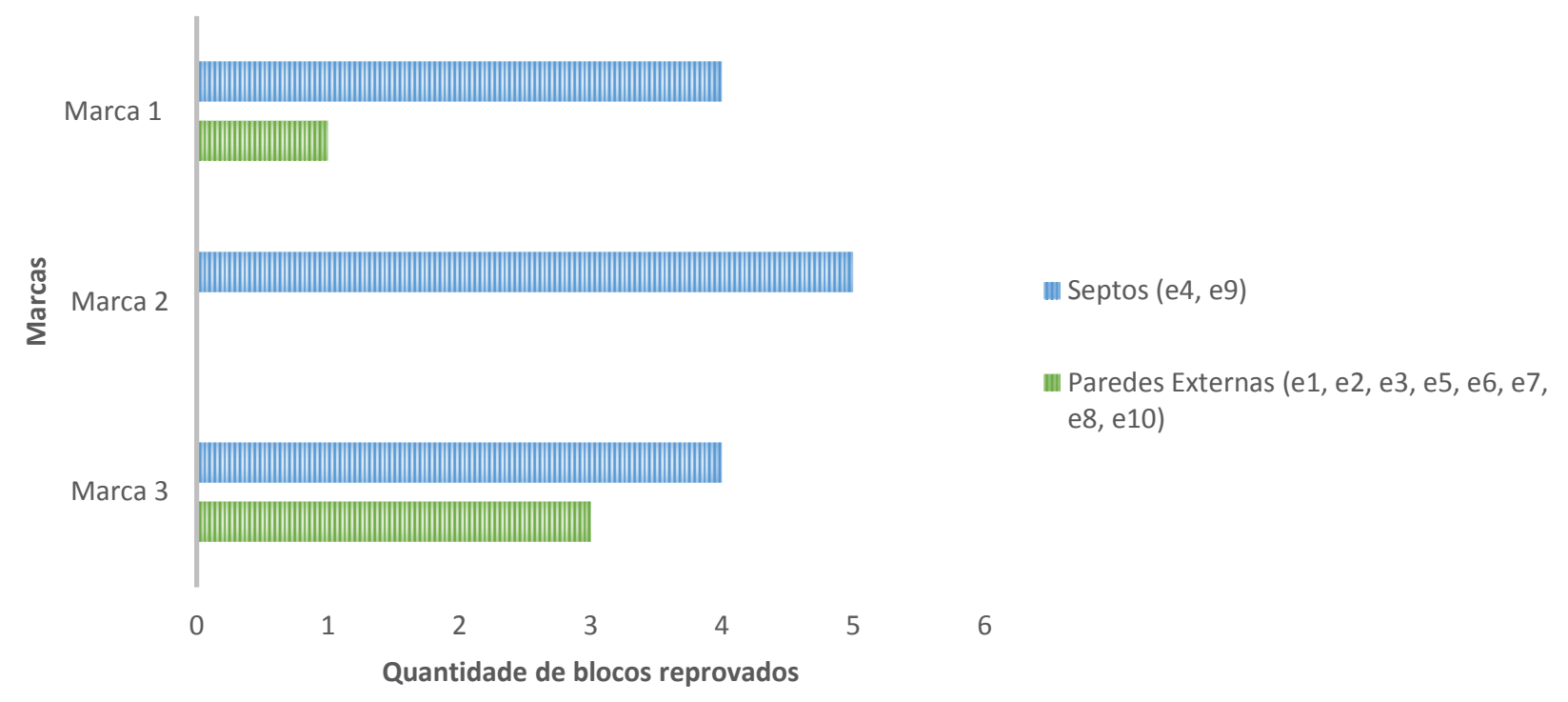

Figura 9 - Quantidade de blocos cerâmicos com aferições dos septos e paredes externas que não atendem o limite da NBR 15720:2017.

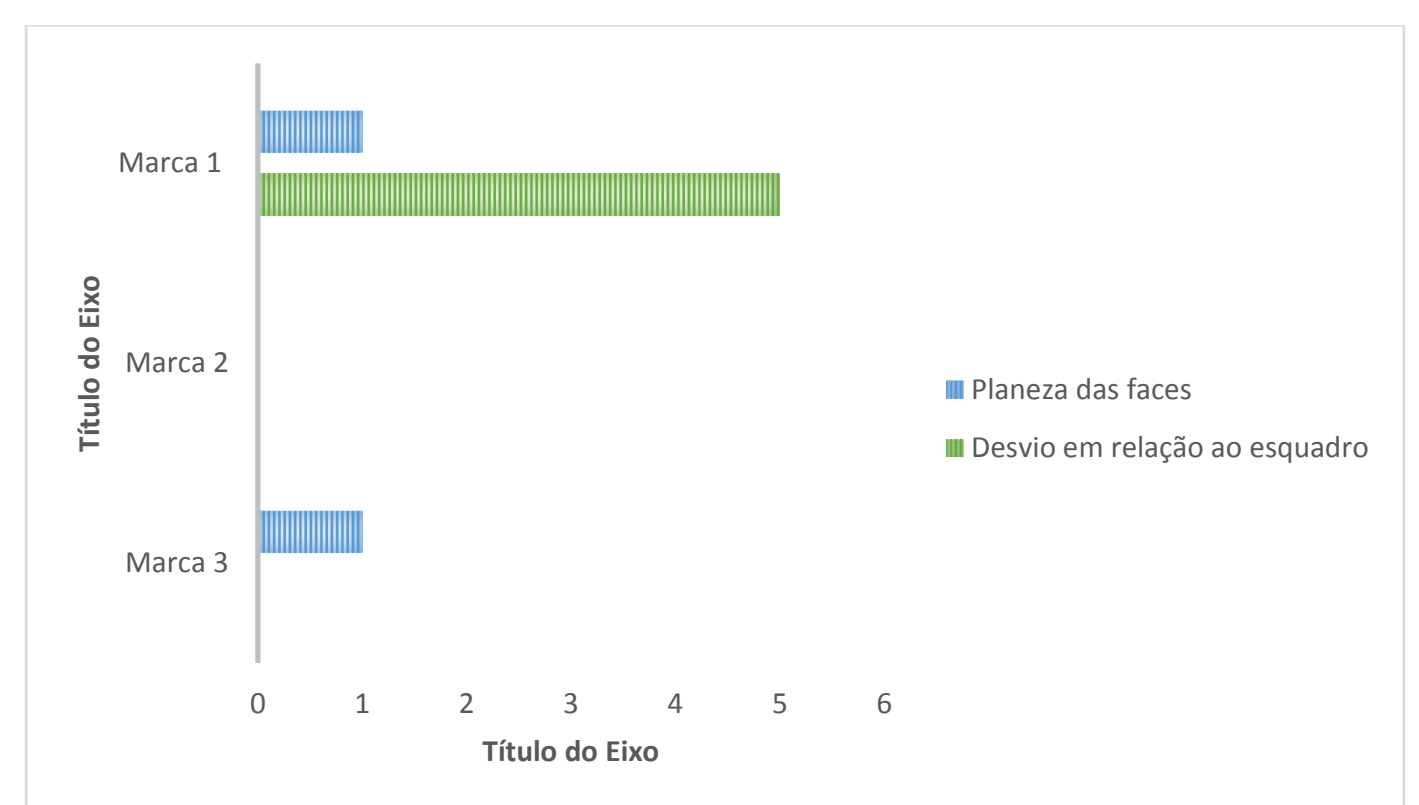

Figura 10 - Quantidade de blocos reprovados nos ensaio de planeza das faces (F) e desvio em relação ao esquadro (D) para as Marcas 1, 2 e 3.

Em relação as características físicas, a média dos resultados para índice de absorção de água (AA) por bloco estão apresentados Figura 11 e Tabela 1. 


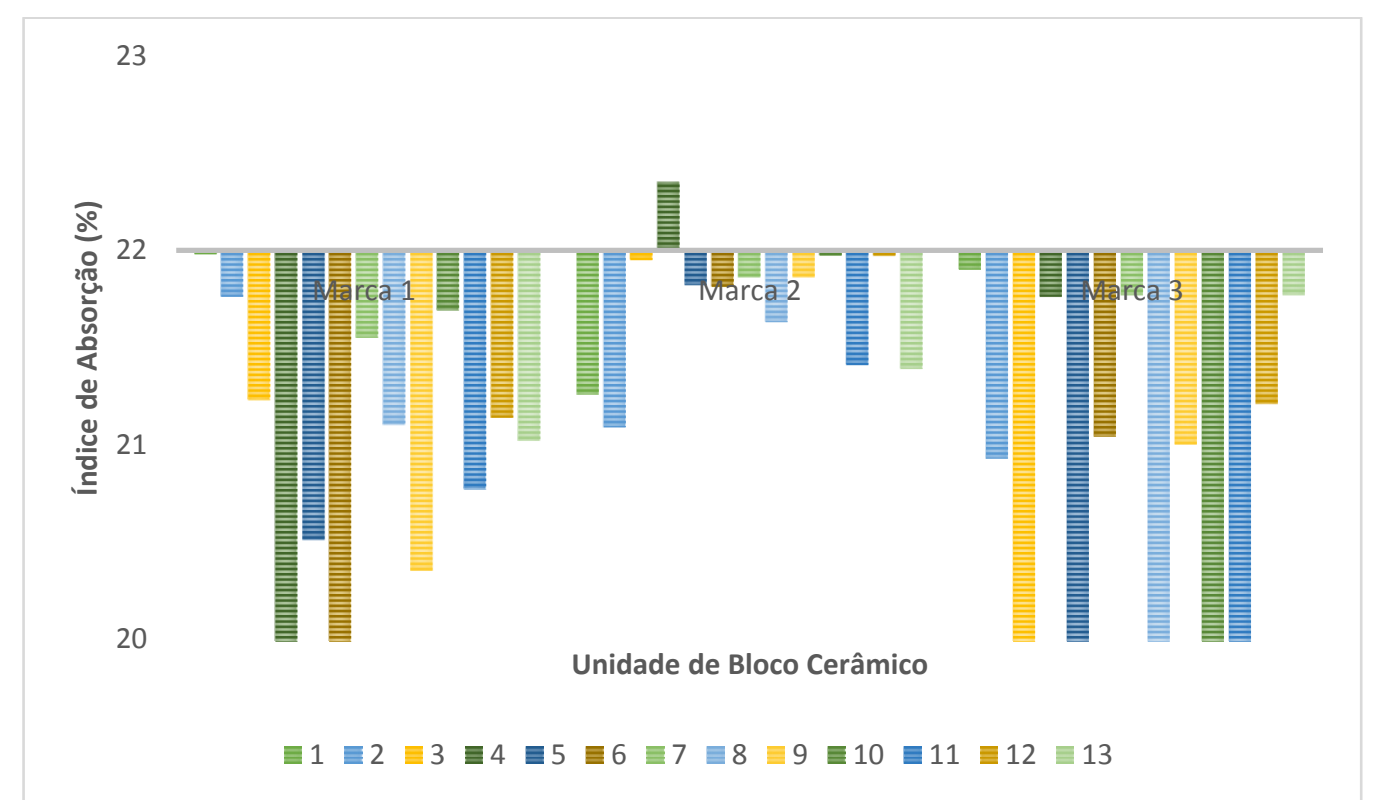

Figura 11 - Resultados obtidos para cada um dos blocos cerâmicos no ensaio de verificação do índice de absorção d'água para as Marcas 1, 2 e 3.

Tabela 1- Resultados obtidos no ensaio de verificação do índice de absorção.

\begin{tabular}{|c|c|c|c|c|c|c|c|c|c|c|c|c|c|}
\hline \multicolumn{14}{|c|}{ Índice de absorção d'água (\%) - limite dos valores $8 \%$ a $22 \%$. } \\
\hline \multirow{2}{*}{ Marca } & \multicolumn{13}{|c|}{ Número das Amostras } \\
\hline & 1 & 2 & 3 & 4 & 5 & 6 & 7 & 8 & 9 & 10 & 11 & 12 & 13 \\
\hline 1 & 21,98 & 21,76 & 21,23 & 19,33 & 20,51 & 19,80 & 21,55 & 21,10 & 20,35 & 21,69 & 20,77 & 21,14 & 21,02 \\
\hline 2 & 21,26 & 21,09 & 21,95 & 22,35 & 21,82 & 21,81 & 21,86 & 21,63 & 21,86 & 21,97 & 21,41 & 21,97 & 21,39 \\
\hline 3 & 21,90 & 20,93 & 18,79 & 21,76 & 18,89 & 21,04 & 21,77 & 19,85 & 21,00 & 19,82 & 19,04 & 21,21 & 21,77 \\
\hline
\end{tabular}

Em relação as características mecânicas, a média dos resultados de resistência à compressão por bloco estão apresentados na Figura 12 e Tabela 2.

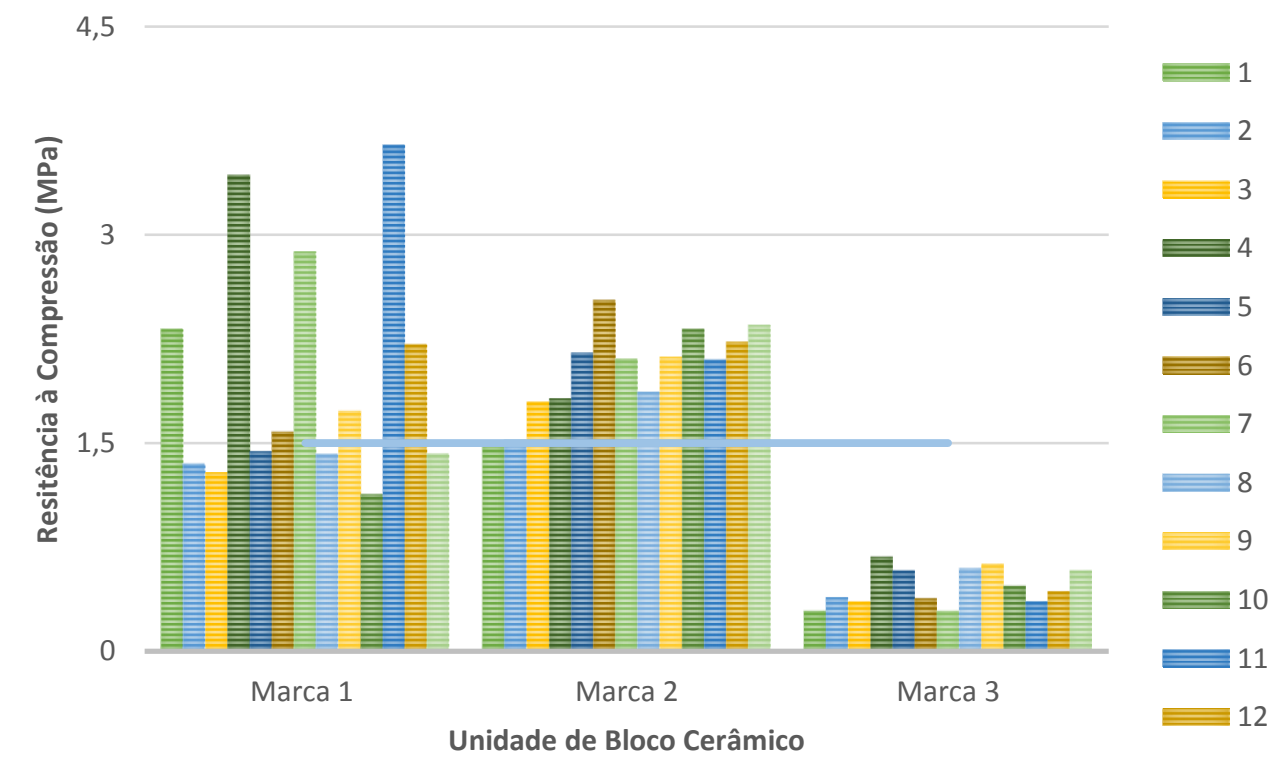

Figura 12 - Resistância à compressão dos blocos cerâmicos para as Marcas 1, 2 e 3. 
Tabela 2- Resultados obtidos no ensaio de resistência à compressão (MPa).

\begin{tabular}{c|c|c|c|c|c|c|c|c|c|c|c|c|c|c}
\hline \multicolumn{11}{c}{ Resistência à Compressão (MPa) - limite dos valores $\geq 1,5$ Mpa } \\
\hline \multirow{2}{*}{ Marca } & \multicolumn{10}{c|}{$\begin{array}{c}\text { Média } \\
\text { (Mpa) }\end{array}$} \\
\hline & $\mathbf{1}$ & $\mathbf{2}$ & $\mathbf{3}$ & $\mathbf{4}$ & $\mathbf{5}$ & $\mathbf{6}$ & $\mathbf{7}$ & $\mathbf{8}$ & $\mathbf{9}$ & $\mathbf{1 0}$ & $\mathbf{1 1}$ & $\mathbf{1 2}$ & $\mathbf{1 3}$ & \\
\hline $\mathbf{1}$ & 2,32 & $\mathbf{1 , 3 5}$ & $\mathbf{1 , 2 9}$ & 3,43 & 1,44 & 1,58 & 2,88 & $\mathbf{1 , 4 2}$ & 1,73 & $\mathbf{1 , 1 3}$ & 3,65 & 2,21 & $\mathbf{1 , 4 2}$ & 1,99 \\
\hline $\mathbf{2}$ & 1,50 & 1,52 & 1,80 & 1,82 & 2,15 & 2,53 & 2,11 & 1,87 & 2,12 & 2,32 & 2,10 & 2,23 & 2,35 & 2,03 \\
\hline $\mathbf{3}$ & $\mathbf{0 , 2 9}$ & $\mathbf{0 , 3 9}$ & $\mathbf{0 , 3 7}$ & $\mathbf{0 , 6 8}$ & $\mathbf{0 , 5 8}$ & $\mathbf{0 , 3 8}$ & $\mathbf{0 , 2 9}$ & $\mathbf{0 , 6 0}$ & $\mathbf{0 , 6 3}$ & $\mathbf{0 , 4 7}$ & $\mathbf{0 , 3 6}$ & $\mathbf{0 , 4 3}$ & $\mathbf{0 , 5 8}$ & $\mathbf{0 , 4 6}$ \\
\hline
\end{tabular}

A partir dos critérios determinados na Seção 8 da NBR 15720-1:2017, os resultados apresentados para caracterização visual seriam suficientes para a rejeição das amostras 1 e 3 , já que as mesmas não possuem a identificação do fabricante em todos os blocos, bem como, apresentam imperfeições numa quantidade superior que a normatizada. No entanto, os demais ensaios foram realizados seguindo a NBR 15720-3:2017 para as três amostras. Para os ensaios de caracterização geométrica, a amostra 1 foi a que melhor manteve a variação das medidas ( $\mathrm{L} \times \mathrm{H} \mathrm{x} \mathrm{C}$ ) dentro do intervalo de $+/-5 \mathrm{~mm}$. Em relação aos parâmetros D e F, a amostra 3 apresentou os menores valores o que significa que seus blocos cerâmicos possuem faces mais planas em comparação com as demais amostras. No parâmetro de resistência a compressão, seguindo a metodologia e critérios de norma, a amostra 2 suportou maiores cargas com média de resistência entre blocos de 2,03 MPa, valor esse acima dos 1,5 MPa regulamentados. Nas características físicas, a amostra 2 possui a média de índice de absorção mais próxima do 22\%. Deste modo, apoiado nos resultados expostos, a Marca $2(19 x 19 x 11,5)$ exibe melhor desempenho em comparação as outras.

\section{CONCLUSÕES}

No decorrer da pesquisa pode-se notar a ineficiência da produção de blocos cerâmicos, pois na analise das três marcas de blocos da região de Brasília foram constados que em sua grande parte as amostras reprovaram por fatores como: resistência, deformações excessivas, dimensões inadequadas (onde fugiam do limite aceitável para o padrão da norma) e ausência da identificação da fábrica e medidas. Observou-se que somente os parâmetros de largura, planeza e absorção passaram em todas as amostras, ainda assim com valores muito próximos do limite aceitável, com isso atestou-se a má qualidade dos blocos cerâmicos comerciais, onde muitas dessas falhas são geradas na produção, pois em sua maioria usam fornos que não tem um bom controle da temperatura, fazendo com que em um mesmo lote tenha blocos com queimas variadas que influência diretamente nas características desse material, por isso se vê a necessidade de investimentos para melhorar a produção dos blocos cerâmicos comerciais.

\section{REFERÊNCIAS}

ANDRADE, Lucimara Aparecida Schambeck. Uma proposta metodológica para a inspeção da qualidade em blocos cerâmicos para alvenaria em canteiros de obras. 2002. 84f. Dissertação (Mestrado em Engenharia de Produção) Programa de Pós-Graduação em Engenharia de Produção, UFSC, Florianópolis.

ASSOCIAÇÃO BRASILEIRA DE NORMAS TÉCNICAS. NBR 15270-1: Componentes cerâmicos - Blocos e tijolos para alvenaria Parte 1: Requisitos. Rio de Janeiro, 2017.

ASSOCIAÇÃO BRASILEIRA DE NORMAS TÉCNICAS. NBR 15270-2: Componentes cerâmicos - Blocos e tijolos para alvenaria Parte 2: Métodos de ensaios. Rio de Janeiro, 2017.

COSTA JR, M. P. Avaliação pós-ocupação e manutenção estratégica de escolas públicas. 2001. Dissertação (Mestrado em Engenharia Civil) - Universidade Federal do Espírito Santo, Espírito Santo, 2001.

MORAIS, D. M. ; SPOSTO, R. M. Propriedades Tecnológicas e Mineralógicas das argilas e suas influências na qualidade de blocos cerâmicos de vedação que abastecem o mercado do Distrito Federal. Cerâmica Industrial, v. 11, p. 35-38, 2006. 